\title{
Combined Experimental and Theoretical Insights into the Corrosion Inhibition Activity on Carbon Steel Iron of Phosphonic Acids
}

\author{
Aurelia Visa (D, Nicoleta Plesu *, Bianca Maranescu, Gheorghe Ilia (D), Ana Borota and Luminita Crisan * \\ “Coriolan Dragulescu” Institute of Chemistry, 24 M. Viteazul Ave, 300223 Timişoara, Romania; \\ avisa@acad-icht.tm.edu.ro (A.V.); bmaranescu@acad-icht.tm.edu.ro (B.M.); ilia@acad-icht.tm.edu.ro (G.I.); \\ ana_borota@acad-icht.tm.edu.ro (A.B.) \\ * Correspondence: nplesu@acad-icht.tm.edu.ro (N.P.); lumi_crisan@acad-icht.tm.edu.ro (L.C.)
}

check for updates

Citation: Visa, A.; Plesu, N.; Maranescu, B.; Ilia, G.; Borota, A.; Crisan, L. Combined Experimental and Theoretical Insights into the Corrosion Inhibition Activity on Carbon Steel Iron of Phosphonic Acids. Molecules 2021, 26, 135. https://doi.org/10.3390/ molecules 26010135

Received: 26 November 2020 Accepted: 26 December 2020 Published: 30 December 2020

Publisher's Note: MDPI stays neutral with regard to jurisdictional clai$\mathrm{ms}$ in published maps and institutional affiliations.

Copyright: (C) 2020 by the authors. Licensee MDPI, Basel, Switzerland. This article is an open access article distributed under the terms and conditions of the Creative Commons Attribution (CC BY) license (https:// creativecommons.org/licenses/by/ $4.0 /)$.

\begin{abstract}
The inhibition effect of $N, N^{\prime}$-phosphonomethylglycine (PMG) and vinyl phosphonic acid (VPA) on the $3 \% \mathrm{NaCl}$ acidic solution corrosion of carbon steel iron was studied at different immersion times by potentiodynamic polarization, electrochemical impedance spectroscopy, attenuated total reflectance Fourier transform infrared (ATR-FTIR) spectroscopy, and computational methods. It is found from the polarization studies that PMG and VPA behave as mixed-type inhibitors in $\mathrm{NaCl}$. Values of charge transfer resistance $\left(R_{c t}\right)$ and double layer capacitance $\left(C_{d l}\right)$ in the absence and presence of inhibitors are determined. The PMG and VPA inhibitors were capable of inhibiting the corrosion process up to $\approx 91 \%$ and $\approx 85 \%$, respectively. In the presence of PMG, the synergic effect of chlorine ions was observed. Density functional theory (DFT) was engaged to establish the adsorption site of PMG, VPA, and their deprotonated states. For studied compounds, the resulted values of $E_{\mathrm{LUMO}}, E_{\mathrm{HOMO}}$, energy gap $(\Delta E)$, dipole moment $(\mu)$, electronic hardness $(\eta)$, global softness $(\sigma)$, electrophilic index $(\omega)$, and the electronic potential map are in concordance with the experimental data results regarding their corrosion inhibition behavior and adsorption on the metal surface.
\end{abstract}

Keywords: corrosion; phosphonic acids; computer modeling; simulation

\section{Introduction}

In recent years, many researchers have been focused on the development of inhibitors for environmental safety purposes. Various organic compounds were successfully applied as corrosion inhibitors. These compounds are containing heteroatoms such as $\mathrm{N}, \mathrm{O}$, and $\mathrm{P}$ in their molecules. In this regard, nitrogen-containing structures such as Schiff bases [1,2], imidazole, triazole, benzimidazole [3,4], phosphonates, metal organic frameworks [5-8], phosphonic acids [9-11], and solid polymer electrolytes based on phosphorus [12-14] have been studied as corrosion inhibitors for iron in acid media.

Organic compounds containing heteroatoms as $\mathrm{N}, \mathrm{P}, \mathrm{O}$, and/or $p$-electrons or nonbonding electrons demonstrate good results for the inhibition of corrosion. The heteroatom inhibitory efficacy decreases in the order: $\mathrm{P}>\mathrm{N}>\mathrm{O}$. Phosphonates and phosphonic acids are well known as inhibitors capacity with a negligible impact on the environment in water treatment. This class of compounds can adsorb almost instantaneously on the metal surfaces and form a protective layer. This behavior reduces the exposure area of the active metal to the corrosive environment.

Corrosion inhibition efficiency correlates with the structure of phosphonate-based molecules [15-17]. Kálmán and coworkers studied the corrosion inhibition for a lowconcentration of 1-hydroxyethane-1,1-diphosphonic acid (HEDP) and high concentration of HEDP on neutral carbon steel. The HEDP inhibits the carbon steel corrosion at low concentration via a precipitation mechanism; thus, the higher concentration of HEDP decreases the inhibitory efficiency due to the dissolution of the oxide layer [18]. 
Organic compounds with phosphorus can cover many application areas such as sensors, corrosion assay materials, cooling water, electro-optics, filtration, ion exchange, and as catalysts [15]. These compounds are resistant to hydrolysis and high temperatures and show good corrosion inhibition properties [19]. The studies have shown that the efficiency of corrosion (IE) is closely related to their structures. Their efficiency arises from their capacity to bind (phosphonic acid group) in a monodentate, bidentate, or tridentate manner to a metal surface $[7,16,20,21]$. Therefore, they can act both as mineral scale and corrosion inhibitors [22,23]. Phosphonates such as diphosphonic acids, aminotris(methylenephosphonic) acid (ATMP), diethylenetriamine-pentamethylenephosphonic acid (DTPMP), hydroxyphosphono acid (HPA), 1-Hydroxyethane-1,1-diphosphonic acid (HEDP), $\mathrm{N}, \mathrm{N}$-dimethylidenephosphonoglycine (DMPG), 1-ethylphosphonoethylidenediphosphonic acid (EEDP), of nitrilotrimethylenephosphonic acid (NTMP), and ethylenediamine tetramethylidenephosphonic acid (EDTMP) were inspected for protecting mild steel from corrosion [18,24-27]. An efficient inhibitor seems to be the phosphonic acids that pose both $\mathrm{N}$ and $\mathrm{O}$ atoms (as in the ATMP molecule), which are both capable of coordinating with $\mathrm{Fe}^{2+}$ in the film. The thiomorpholin-4-ylmethyl-phosphonic acid (TMPA) and morpholin-4-methylphosphonic acid (MPA) offer corrosion protection of carbon steel in natural seawater [28]. Tetraphosphonates with six or eight carbon atoms on the chain generate a well-organized packing on the carbon steel surface, while the two carbons in tetraphosphonate form a thin, incomplete, and porous layer on the carbon steel surface [21].

Valuable information can be extracted from the frontier orbitals that allowed us to investigate their tendency to form a protection film on the metal surface $[29,30]$. The literature mentioned the corrosion assay of 2-phosphate group-1,2,4-tricarboxylate butane (PBTCA), hydroxyethylidene disphosphonic acid (HEDP), and aminotrimethylene phosphonic acid (ATMP) and reported that the corrosion inhibition rate of these three organic phosphorus reagents can be presented in the following order BTCA $>$ HEDP $>$ ATMP. Corresponding to the molecular layout analysis and the frontier orbital theory, these three organophosphorus were used as electron buffers. They are capable of receiving the free electron of the outer orbit of the iron atom and forming a stable coordination bond. The protective film formed on the metal surface was further capable of obstructing the metal corrosion. In addition, the inhibitor can provide electrons to zinc ions present in the water, forming complex compounds, and permit safe water circulation in the cooling system [31].

Therefore, the present study is focused on two phosphorous acids and their corrosion inhibition of iron in $\mathrm{NaCl}$ solution. The inhibition property offered by these acids was investigated electrochemically, and the quantum chemical method was employed to calculate the molecular structure parameters and to explore the mechanism of corrosion inhibition. Theoretical studies were undertaken to offer molecular level information on the corrosion inhibition action of investigated materials on iron surfaces and to additional support experimental data.

\section{Materials and Methods}

\subsection{Experimental}

All chemicals were of reagent grade quality achieved from commercial sources and used without further purification. N,N-bis(phosphonomethyl)-glycine (PMG) and vinylphosphonic acid (VPA) were purchased from Merck (Milipore, Darmstadt, Germany), and $\mathrm{NaCl}, \mathrm{HNO}_{3} 65 \%$ were purchased from Sigma Aldrich Chemie $\mathrm{GmbH}$ (München, Germany). Low-carbon steel specimen contains chemical composition (wt $\%$ ) of C: $0.20 \%$, Mn: $0.45 \%$, P: $0.04 \%$, S: $0.05 \%$ and Fe balance, were made from an iron bar, which was purchased from EPI Sistem (Brasov, Romania).

2.1.1. Potentiodynamic Polarization (CP) Testing and Electrochemical Impedance Spectroscopy (EIS) Measurements

Electrochemical tests: electrochemical impedance spectroscopy (EIS) spectra and polarization curves $(\mathrm{CP})$ were performed to assess the corrosion inhibitory effect of PMG 
and $\mathrm{VPA}$ in $3 \% \mathrm{NaCl}$ solution, adjusted with $\mathrm{HNO}_{3}(65 \%)$ to $\mathrm{pH} \approx 2.3$ (The $\mathrm{pH}$ was measured using a $\mathrm{pH}$ meter (Mettler Toledo, Giessen, Germany)). The control electrolyte solution was $3 \% \mathrm{NaCl}$ with $\mathrm{pH} \approx 2.3$. A Dcorr cell corrosion cell and Autolab 302N EcoChemie (Netherlander, 2007) was employed. The working electrode was a coupon carbon steel with an exposed area of $0.785 \mathrm{~cm}^{2}$. Two graphite bars and $\mathrm{Ag} / \mathrm{AgCl}$ were used as counter electrodes and the reference electrode, respectively. The experimental data were used to estimate the corrosion rate $(C R)$ and electrochemical parameters such as corrosion potential-Ecorr, corrosion density current-Jcorr, and polarization resistance$R p$ of carbon steel in $\mathrm{NaCl} 3 \%$ solution, at $\mathrm{pH} \approx 2.3$ from Tafel plots. EIS measurements were conducted at open circuit potential (OPC) values, at $22 \pm 1{ }^{\circ} \mathrm{C}$ under potentiostatic mode using ac signals of amplitude $10 \mathrm{mV}$ peak to peak in the frequency range from 10.000 to $0.01 \mathrm{~Hz}$. The experimental electrochemical impedance data were fitted to the electrical equivalent circuit (EEC) by a complex non-linear least squares Levenberg-Marquardt procedure using ZView 3.0 software (Scribner Associates, Inc., Southern Pines, NC, USA). The EIS and CP tests were performed after one and two hours of immersion. All the experiments were conducted in triplicate.

\subsubsection{Attenuated Total Reflectance Infrared (ATR)}

All spectra were recorded with an FT/IR-4200 JASCO Spectrophotometer, equipped with PIKe ATR (MIRacle), DTGS detector, Ge crystal plate with a resolution of $4 \mathrm{~cm}^{-1}$ in the range of 4000-600 $\mathrm{cm}^{-1}$. All data were analyzed by the Spectral Manager Version 2 software.

\subsubsection{Optical Microscopy}

The Zeiss Stemi 508 microscope (CarlZeiss Microscopy GmbH, Gottingen, Germany) was used to investigate the morphology of the films formed on the surface of the carbon steel.

\subsection{Theoretical Chemical Calculations}

The molecular structures of VPA, PMG, and their mono and bi deprotonated species at phosphonic moiety group $\mathrm{VPA}^{1-}, \mathrm{VPA}^{2-}, \mathrm{PMG}^{1-}, \mathrm{PMG}^{3-}$, and $\mathrm{PMG}^{4-}$ were preoptimized using the MM+ (Molecular Mechanics) Force Field and further refined using the semi-empirical PM3 (Parametric Method 3) method included in HyperChem 7.52 (Hypercube, Inc., Gainesville, FL, USA) package [32]. Geometry optimization was achieved by setting a Polak-Ribere algorithm with an SCF (Self Consistent Field) convergence limit of $0.00001 \mathrm{kcal} / \mathrm{mol}$, and an RMS (Root-Mean-Square) gradient norm limit of $0.01 \mathrm{kcal} /(\AA \cdot \mathrm{mol})$. The complete geometric optimization of the PM3 geometries was carried out with a Jaguar module of the Schrödinger package by applying density functional theory (DFT) incorporating the B3LYP-D3/6-31G ${ }^{* *}$ basis set $[33,34]$. Furthermore, for both neutral and the mono and bi deprotonated structure of VPA and PMG, frequency calculations were performed to check if there are true minima. The lack of any negative frequencies certified the true energies minima of the compounds. To portray the anticorrosion action of VPA and PMG, their lowest energy conformations were selected to further calculate several quantum chemical descriptors such as the lowest unoccupied molecular orbital (LUMO) and the highest occupied molecular orbital (HOMO), the ionization potential (IP; Equation (1)), the electron affinity (EA; Equation (2)), the energy gap $(\Delta E$; Equation (3)), hardness ( $\eta$, Equation (4)), softness $(\sigma$; Equation (5)), and electrophilicity index ( $\omega$; Equation (6)). The results of the calculated descriptors provide key information about the electronic structure, conformation, and reactivity of VPA and PMG compounds, which support their anticorrosive action.

$$
\begin{gathered}
I P=-E_{\text {HOMO }} \\
E A=-E_{\text {LUMO }} \\
\Delta E=E_{\text {LUMO }}-E_{\text {HOMO }}
\end{gathered}
$$




$$
\begin{aligned}
\eta=I P-E A & =\frac{E_{L U M O}-E_{H O M O}}{2} \\
\sigma & =\frac{1}{\eta} \\
\omega & =\frac{\mu^{2}}{2 \eta}
\end{aligned}
$$

For the compound that shows the highest probability of adsorption on the metal surface, the electrostatic potential was displayed. This parameter depicts the interaction between the compound and a positive point charge (in our study, $\mathrm{Fe}^{2+}$ ). It is very useful for identifying sites of reaction in a compound. It is expected that molecule where the electrostatic potential is strongly negative to be susceptible to an electrophilic attack.

\section{Results}

\subsection{Potentiodynamic Polarization Study}

The polarization measurement results were used to evaluate the protective properties of inhibitors on the corrosion of carbon steel in $\mathrm{NaCl}$ solution at a $\mathrm{pH}=2.3$, at two different film-forming times: $1 \mathrm{~h}$ and two hours. Potentiodynamic polarization measurements were carried out by scanning the electrode potential from -1200 to $-200 \mathrm{mV}$ (vs. $\mathrm{Ag} / \mathrm{AgCl}$ ) with a scan rate of $0.01 \mathrm{mV} \cdot \mathrm{s}^{-1}$.

Figure 1 displays the potentiodynamic polarization curves recorded in an acid medium of $3 \% \mathrm{NaCl}$, which were obtained before and after the introduction of $2 \mathrm{mM}$ inhibitors (this concentration was used based on previous results) [8]. Various corrosion parameters (cathodic $-\beta c$ and anodic $-\beta a$ Tafel slope, corrosion potential—Ecorr, corrosion current density-Jcorr, polarization resistance $-R p$, and corrosion rate $-C R$ ) were determined from Tafel plots at different immersion times. The values are summarized in Table 1.

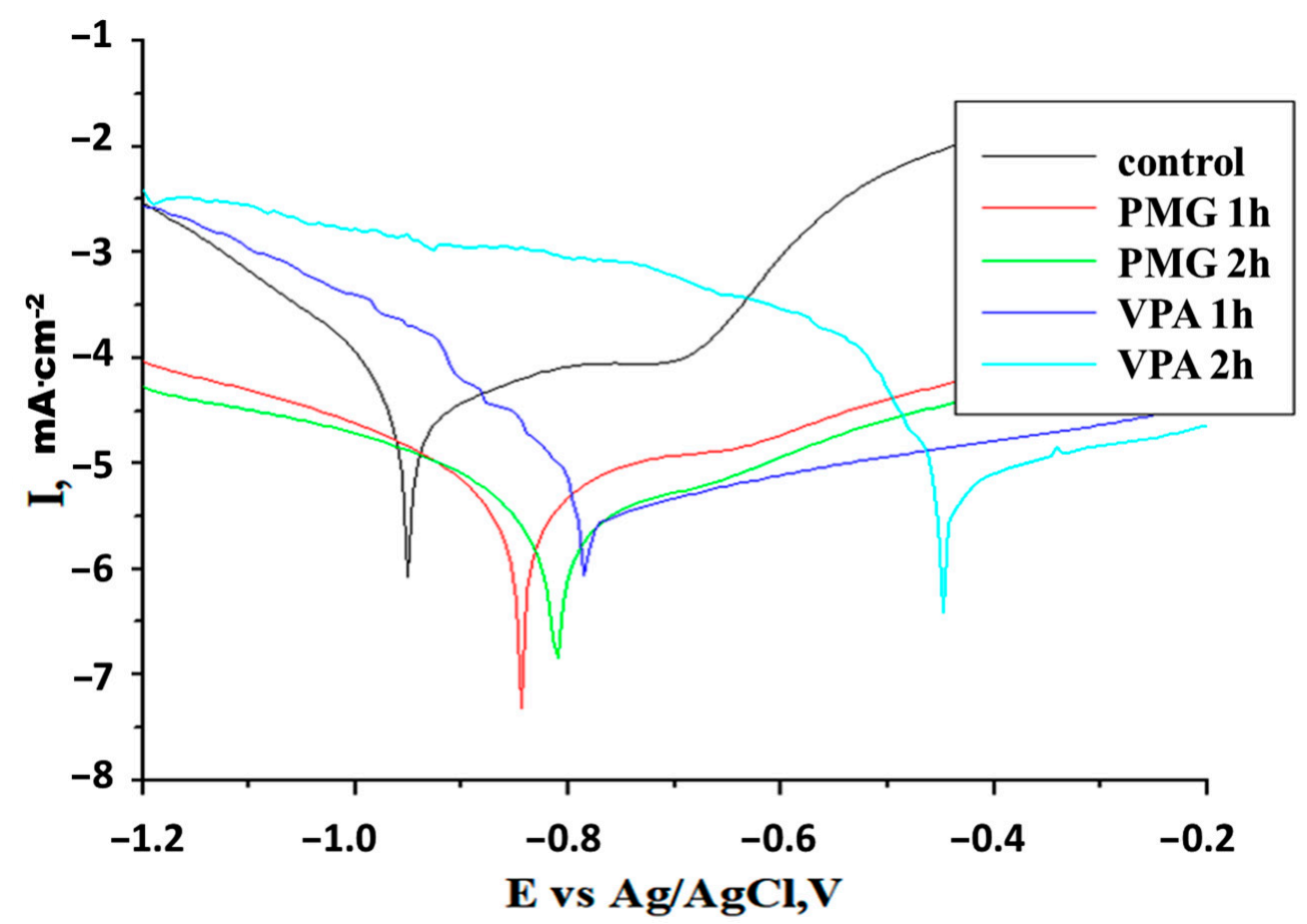

Figure 1. Potentiodynamic polarization curves for carbon steel after different immersion times in $3 \%$ $\mathrm{NaCl}$ solutions, $\mathrm{pH}=2.3$ without (control) and with $2 \mathrm{mM}$ inhibitor (scan rate $=1 \mathrm{mV} / \mathrm{s}$ ), at $22{ }^{\circ} \mathrm{C}$. 
Table 1. Electrochemical parameters for carbon steel maintained in $3 \% \mathrm{NaCl}$ solution $\mathrm{pH}=2.3$ with different inhibitors at $22{ }^{\circ} \mathrm{C}$.

\begin{tabular}{|c|c|c|c|c|c|c|c|}
\hline Sample/*SD & $\begin{array}{c}\text { Jcorr, } \\
\mathrm{A} \cdot \mathrm{cm}^{-2}\end{array}$ & Ecorr, $\mathrm{V}$ & $\begin{array}{c}R p \\
\mathrm{Ohm} \cdot \mathrm{cm}^{-2}\end{array}$ & $\begin{array}{c}\beta a, \\
\text { V/dec }\end{array}$ & $\begin{array}{r}-\beta c \\
\text { V/dec }\end{array}$ & $\begin{array}{c}C R, \\
\mathrm{~mm} \cdot \text { year }^{-1}\end{array}$ & $\begin{array}{l}I E, \\
\%\end{array}$ \\
\hline control & $4.31 \times 10^{-5} \pm 1.24 \times 10^{-6}$ & $-0.923 \pm 0.032$ & $5.321 \times 10^{2} \pm 0.272 \times 10^{2}$ & $0.305 \pm 0.032$ & $0.136 \pm 0.008$ & $5.016 \times 10^{-1} \pm 1.021 \times 10^{-2}$ & - \\
\hline PMG $1 \mathrm{~h}$ & $5.76 \times 10^{-6} \pm 0.85 \times 10^{-7}$ & $-0.828 \pm 0.021$ & $6.733 \times 10^{3} \pm 5.653 \times 10^{2}$ & $0.288 \pm 0.021$ & $0.243 \pm 0.013$ & $6.009 \times 10^{-2} \pm 2.191 \times 10^{-4}$ & $86.627 \pm 2.042$ \\
\hline PMG $2 \mathrm{~h}$ & $3.67 \times 10^{-6} \pm 1.30 \times 10^{-8}$ & $-0.811 \pm 0.054$ & $1.363 \times 10^{4} \pm 6.003 \times 10^{2}$ & $0.290 \pm 0.009$ & $0.267 \pm 0.024$ & $4.271 \times 10^{-2} \pm 2.323 \times 10^{-4}$ & $91.485 \pm 0.532$ \\
\hline VPA $1 \mathrm{~h}$ & $6.16 \times 10^{-6} \pm 0.05 \times 10^{-7}$ & $-0.744 \pm 0.082$ & $7.740 \times 10^{3} \pm 1.732 \times 10^{2}$ & $0.650 \pm 0.002$ & $0.333 \pm 0.003$ & $7.171 \times 10^{-2} \pm 6.24 \times 10^{-4}$ & $85.703 \pm 1.003$ \\
\hline VPA $2 \mathrm{~h}$ & $5.96 \times 10^{-6} \pm 1.18 \times 10^{-7}$ & $-0.577 \pm 0.067$ & $2.404 \times 10^{3} \pm 0.834 \times 10^{2}$ & $0.613 \pm 0.004$ & $0.329 \pm 0.006$ & $6.941 \times 10^{-2} \pm 1.71 \times 10^{-3}$ & $86.162 \pm 0.934$ \\
\hline
\end{tabular}

*SD—standard deviation. 
These values obtained from the extrapolation of anodic and cathodic Tafel lines located next to the linearized current regions represent the mean value of three determinations.

It can be observed that the Jcorr values for all inhibitors (Table 1) were lower than those for the "control". The higher anodic currents for iron indicated that the iron suffers corrosion via its dissolution into ferrous and ferric cations. The differences observed for the values of Jcorr and $R p$ indicate better protection of carbon steel in the presence of PMG. In the presence of PMG, the lowest Jcorr and highest $R p$ were obtained: $\approx 5.76 \times 10^{-6} \mathrm{~A} \cdot \mathrm{cm}^{-2}$ and $6.733 \times 10^{3} \mathrm{Ohm} \cdot \mathrm{cm}^{-2}$ after $1 \mathrm{~h}$ and $3.67 \times 10^{-6} \mathrm{~A} \cdot \mathrm{cm}^{-2}$ and $1.363 \times 10^{4} \mathrm{Ohm} \cdot \mathrm{cm}^{-2}$ after $2 \mathrm{~h}$ of immersion. Experimental data show that the protection offered by the tested inhibitors is maintained over time and changes due to the adsorption of molecules at the metal surface. As the immersion time increases, the corrosion currents decrease, and the $R p$ increases in the case of PMG and decreases slightly in the case of VPA. Also, the values of the corrosion rate, $C R$ was lower in the presence of PMG. The anodic polarization curves are shifted to positive values for all inhibitors. The values of cathodic and anodic Tafel slopes suggest some modification in the inhibition corrosion mechanism due to the adsorption process and to the formation of a protective layer at the active metal surface.

The differences obtained in the values of Tafel slopes indicate a different way by which the inhibitors are absorbed on the metal surface. Inhibitors are adsorbed at the metal/solution interface and are capable to block the active site, providing more protection to the metallic surface. The corrosion potential (Ecorr) is shifted to a more noble value (positive value) compared with that of the bare metal.

The shape for the anodic and cathodic parts suggests that the addition of inhibitors reduced the hydrogen evolution and oxidation of the metal. The addition of inhibitors affected anodic and cathodic reactions therefore these inhibitors can be considered as mixed-type inhibitors with an anodic prime effect.

For the VPA, the $\beta a$ is smaller than $\beta c$, implying that the electrode reaction of the carbon steel surface is mainly controlled by cathode reduction. In the case of the PMG, the $\beta a$ is larger than $\beta c$ as the electrode reaction is most probably a mixed controlled one.

Based on the corrosion current density data, the inhibition efficiency was calculated according to Equation (7):

$$
I E=\frac{J_{\text {corr }}-J_{\text {inh }}}{J_{\text {corr }}} \times 100
$$

where $I E$ represents the inhibitory efficiency expressed in \%, and Jcorr and Jinh are the corrosion current density without and with inhibitor, respectively.

PMG and VPA offer a good inhibition efficiency with max values of $91 \%$ and $86 \%$ respectively, as a result of the formation of a passivating film on the metallic surface. It is clear that the surface coverage $(\theta)$ and inhibition efficiency $(I E)$ varies with immersion time and depends on the inhibitor nature. At this concentration ( $2 \mathrm{mM})$ of inhibitor with the increase of immersion time, the adsorption of inhibitor molecules take place, and more inhibitor molecules will be adsorbed onto the iron surface, which is capable of forming and maintaining the protective layer. The differences observed with the increase of immersion time are the result of the reorientation of inhibitor molecules and/or their adsorption/desorption from the surface.

\subsection{ATR Spectral Studies}

The ATR spectral studies were conducted to investigate the protective film formed on the metal surface by the inhibitor molecules. The spectra are presented in Figure 2a,b.

The assignment of bands for PMG presents difficulties, due to the presence of some regions with very broad and structured bands as $-\mathrm{NH}^{+},-\mathrm{P}=\mathrm{O},-\mathrm{P}-\mathrm{OH},-\mathrm{COO}^{-}$, and $-\mathrm{COOH}$, groups are present in solution (Figure 2a). In the ATR spectra of the film formed in the presence of PMG in 3500-2800 $\mathrm{cm}^{-1}$ frequency domain, very broad bands were observed that reflect a highly complex spectral shape most probably due to intermolecular and/or intramolecular hydrogen bonding formed by $-\mathrm{PO}_{3} \mathrm{H}_{2}, \mathrm{NH}^{+}, \mathrm{COH}$, and the $\mathrm{COOH}$ groups. 


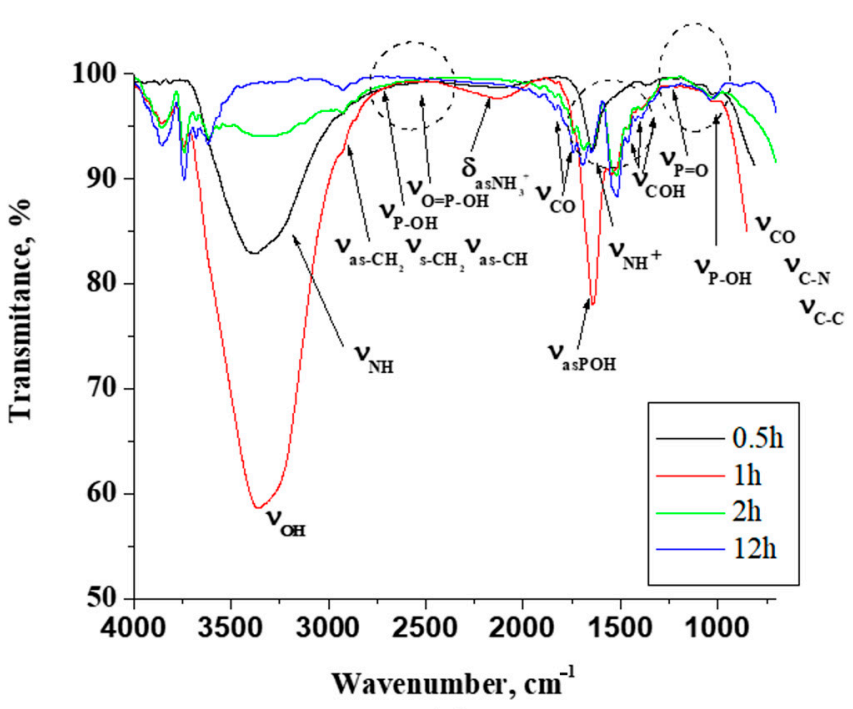

(a)

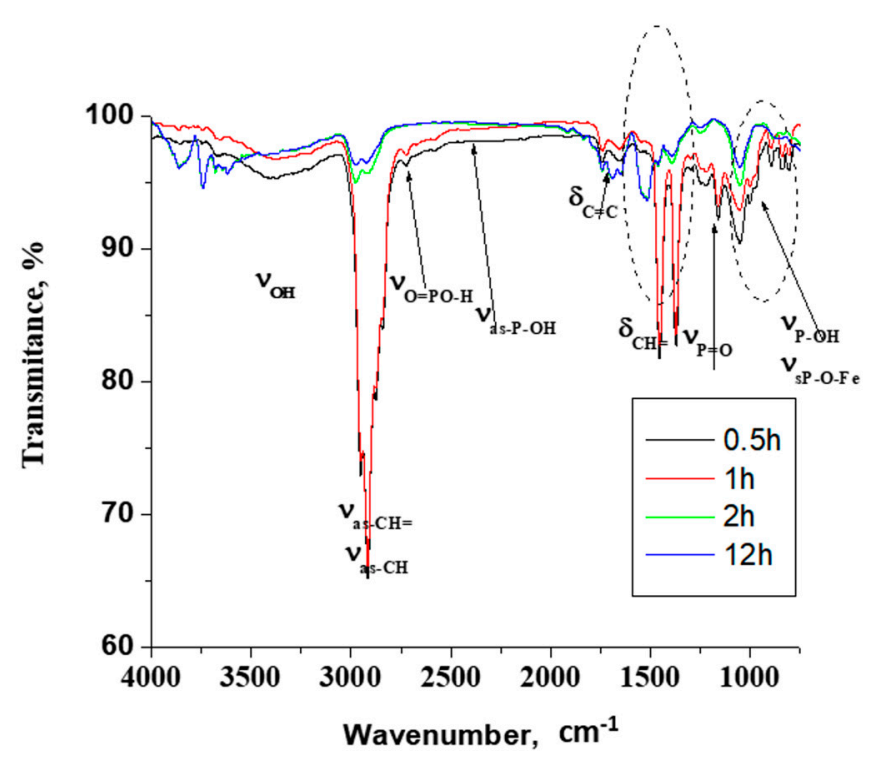

(b)

Figure 2. ATR-FTIR spectra for (a) $N, N^{\prime}$-phosphonomethylglycine (PMG) and (b) for vinyl phosphonic acid (VPA).

The film formation was confirmed by the disappearance of the hydrogen bond between the inhibitor molecules, which confirms the bond formation between the inhibitor and the metal surface during the adsorption process [35]. The bands at $3255 \mathrm{~cm}^{-1}$ were attributed to $v_{\mathrm{as} \mathrm{NH}}{ }^{+}$and at $3212 \mathrm{~cm}^{-1}$ to $v_{\mathrm{sNH}}{ }^{+}$. The $\mathrm{CH}_{2}$ and $\mathrm{CH}$ stretching modes $v_{\mathrm{sCH} 2}, v_{\mathrm{asCH} 2}$, and $v_{\mathrm{sCH}}$ appear as a shoulder at 2945 and at $2927 \mathrm{~cm}^{-1}$ and at $2905 \mathrm{~cm}^{-1}$, respectively. The weak broad absorption at near $2700 \mathrm{~cm}^{-1}$ was attributed to P-O-H [36]. The bands at $2550 \mathrm{~cm}^{-1}$ and at $\approx 2190 \mathrm{~cm}^{-1}$ were associated with $\mathrm{O}=\mathrm{P}-\mathrm{OH}$ vibrations. The phosphonate group vibrations $\left(-\mathrm{PO}_{3} \mathrm{H}_{2}\right)$ were attributed to the bands at $1643 \mathrm{~cm}^{-1}$, at $1225 \mathrm{~cm}^{-1}$, and at $1100-1140 \mathrm{~cm}^{-1}$ due to $v_{\mathrm{asP}-\mathrm{OH}}, v_{\mathrm{P}=\mathrm{O}}$, and $v_{\mathrm{P}-\mathrm{OH}}$ stretching mode, respectively $[37,38]$.

The carboxyl group presents bands due to the carbonyl and alcohol group vibrations. The bands at $1819 \mathrm{~cm}^{-1}$ and $1790 \mathrm{~cm}^{-1}$ were assigned to the $v_{\mathrm{C}=\mathrm{O}}$ stretching mode. The main -COH bending modes are grouped at 1466, 1415, and $1383 \mathrm{~cm}^{-1}$. The $-\mathrm{NH}^{+}$group stretching modes are expected to appear not only above $3200 \mathrm{~cm}^{-1}$ but at $\approx 1600 \mathrm{~cm}^{-1}$ associated with $\delta_{\mathrm{NH}^{+}}$and to $\mathrm{C}-\mathrm{NH}$ rocking deformation and wagging bond vibrations, and they overlapped with the $\mathrm{COH}$ and $-\mathrm{PO}_{3} \mathrm{H}_{2}$ groups. These bands were attributed mainly to the $v_{\mathrm{SO}=\mathrm{P}-\mathrm{OH}}$ absorption band, but it is possible for this to overlap with the $v_{\mathrm{SCOO}}{ }^{-}$, $\delta_{\mathrm{asNH}}{ }^{+}$vibration and $\delta \mathrm{CH}_{2}$ absorption bands. The range $900-1200 \mathrm{~cm}^{-1}$ is a complex spectral region characteristic of vibrations related to the $-\mathrm{PO}_{3}$ moiety. Bands at 1050, 929, and $902 \mathrm{~cm}^{-1}$ correspond to the $v_{\mathrm{asP}=\mathrm{O}}$ bond, $\mathrm{C}-\mathrm{N}$ bond stretching, and $\mathrm{C}-\mathrm{C}$ skeletal stretching [39]. The band at $1038 \mathrm{~cm}^{-1}$ was attributed to a zwitterionic structure involving intramolecular hydrogen bonding between $\mathrm{P}_{-} \mathrm{O}^{-}$and $\mathrm{NH}^{+}$, which is an assumption in agreement with results found for glyphosate [40].

The differences in the vibration frequencies of the $\mathrm{O}=\mathrm{P}-\mathrm{OH}$ are probably due to the participation of this group in the formation of hydrogen bonds with different strengths. The phosphonic group can bind to the iron via a direct $\mathrm{P}-\mathrm{O}-\mathrm{Fe}$ bond in different modes, i.e., mono, bi-, or tridentate, as one, two, or all three oxygen atoms from the phosphonic group are involved [41]. The ATR spectra reveal a time-dependent adsorption process. It is observed that the carboxylate bands (Figure 2a, middle marked zone) occur in these films at frequencies and an intensity similar to PMG. This suggests a weak carboxylate interaction with a metallic substrate.

Decreasing the intensity and shifting to the lower wavelength of the characteristic absorption band at $3388 \mathrm{~cm}^{-1}$ related to the $\mathrm{OH}$ stretching mode of the molecules shows that as the immersion time increases, the number of free $\mathrm{OH}$ groups in films decreases, and they can participate in the formation of intermolecular hydrogen bonds. Moreover, the 
appearance of a new, broad absorption band at prolonged immersion time at $2550 \mathrm{~cm}^{-1}$ associated with $\mathrm{O}=\mathrm{P}-\mathrm{OH}$... O sustains also the formation of hydrogen bonds (Figure 2a, highlighted zone) [38].

The decrease of the band at $\approx 1600 \mathrm{~cm}^{-1}$ attributed to the asymmetric bending band of the $-\mathrm{NH}^{+}$also proves that the nitrogen atom is also involved in the adsorption process, through the formation of a complex. With the increase of immersion time, the characteristic band at $1225 \mathrm{~cm}^{-1}$, which corresponds to the $\mathrm{P}=\mathrm{O}$ stretching mode, decreases as the PMG molecules self-assembled onto the iron substrates by a multidentate binding (lower gap energy indicated by computational studies) [42].

The phosphonate band at $1100-1140 \mathrm{~cm}^{-1}$ in PMG is assigned to $\mathrm{P}_{-} \mathrm{O}^{-}$stretching motions $\left(v_{\mathrm{P}-\mathrm{O}}^{-}\right)$. Its absence in the corresponding films indicates the multidentate binding by all three oxygens of phosphonate group (Figure 2a, highlighted). Moreover, the corresponding band for films appears at lower wavenumber $\left(1050 \mathrm{~cm}^{-1}\right)$ characteristic for deprotonated species. This suggests further interaction of the $\mathrm{P}=\mathrm{O}$ moiety and the bond formation with the iron surface. This observation is corroborated by the higher Rct attributed to strong bond formation at $2 \mathrm{~h}$ of immersion time and computational result. In consequence, it is possible to assume that the interaction between the amine group and $\mathrm{Fe}$ surface brings the $\mathrm{PO}_{3}{ }^{2-}$ groups closer to the metal surface. This assumption is supported also by the high degree of surface coverage and by the high $\Delta G^{\circ}$ ads value.

The ATR spectra of carbon steel immersed in VPA reveal the film formed on the surface absorption peaks linked to the bonds $\mathrm{P}=\mathrm{O},-\mathrm{P}-\mathrm{OH}$, and $\mathrm{C}=\mathrm{C}$ respectively (Figure $2 \mathrm{~b}$ ).

The O-H, $-\mathrm{C}-\mathrm{H}, \mathrm{CH}=$, and $\mathrm{C}=\mathrm{C}$ bands appear at $3400-3200 \mathrm{~cm}^{-1}$, at $2940-2900 \mathrm{~cm}^{-1}$, and at $1678-1600 \mathrm{~cm}^{-1}$, respectively. The band assigned to $\mathrm{PO}_{3}{ }^{2-}$ appears approximately as in the case of PMG as follows: at $3340 \mathrm{~cm}^{-1}$, it was assigned to the O-H stretching band; at $2900 \mathrm{~cm}^{-1}$, it was assigned to $\mathrm{C}-\mathrm{H}$ stretching vibration; at $2700 \mathrm{~cm}^{-1}$, it was assigned to the stretching of $\mathrm{O}=\mathrm{P}-\mathrm{O}-\mathrm{H}$; at $2333 \mathrm{~cm}^{-1}$, it was assigned to $\mathrm{P}-\mathrm{OH}$ stretching; at $1350 \mathrm{~cm}^{-1}$ and $1255 \mathrm{~cm}^{-1}$, it was assigned to the stretching of $\mathrm{P}=\mathrm{O}$; and at $980 \mathrm{~cm}^{-1}$, it was assigned to the O-P-O band and/or to P-OH. The literature data mentioned that the low intensity of the bands attributed to the $\mathrm{P}-\mathrm{OH}$ stretching mode and the presence of $\mathrm{PO}_{3}{ }^{2-}$ stretching modes (deprotonation of the phosphonic acid group) in the spectrum is an indication for a bidentate binding [43], which is observed also in our case: a lower gap energy indicated by computational studies. Other researchers conclude that the bidentate binuclear complex takes place at high $\mathrm{pH}$ and low surface coverage, whereas the protonated monodentate mononuclear complex is dominant at low $\mathrm{pH}$ and high surface coverage [44]. It is more probable that in the film formed in the presence of VPA, both monodentate and bidentate complexes are present (Figure $2 b$ ). The increase of $\mathrm{P}-\mathrm{OH}$ and $\mathrm{P}=\mathrm{O}$ stretching bands with the increase of the immersion time reveal a decreasing tendency of a multidentate bind. With the increase of surface coverage, the binding modes can turn to a monodentate binding. Even the desorption of this acid is possible. As a consequence, $\mathrm{R}_{\mathrm{ct}}$ and IE will decrease. The band at $1692 \mathrm{~cm}^{-1}$ was attributed to $\mathrm{C}=\mathrm{C}$ stretch. The position of the $\mathrm{C}=\mathrm{C}$ stretching frequency varies slightly as a function of orientation around the double bond and is less informative than the information brought by vibrations of $\mathrm{CH}=$. The vibration $\mathrm{CH}=$ out-ofplane and in-plane bending appear at $1420 \mathrm{~cm}^{-1}$ and $968 \mathrm{~cm}^{-1}$, respectively. The decrease of these bands with the increase of immersion time also suggests some hydrogen bonding or deprotonation processes that dominate the adsorption of VPA at the metal surface, which are responsible for reactions that decrease the strength of the formed protective layer, as shown in Figure $2 b$ in the highlighted zones.

\subsection{Electrochemical Impedance Spectroscopy (EIS) Measurements}

Impedance spectra represented in both complex impedance diagrams (Nyquist plot) and Bode are illustrated in Figure 3. In the Nyquist graph (Figure 3a), the imaginary component of the impedance is plotted as a function of the real component. The Bode representation displays the logarithm of the impedance modulus $|\mathrm{Z}|$ (Figure $3 b$ ) and phase angles as a function of the logarithm of the frequency $f$ (Figure 3c). 


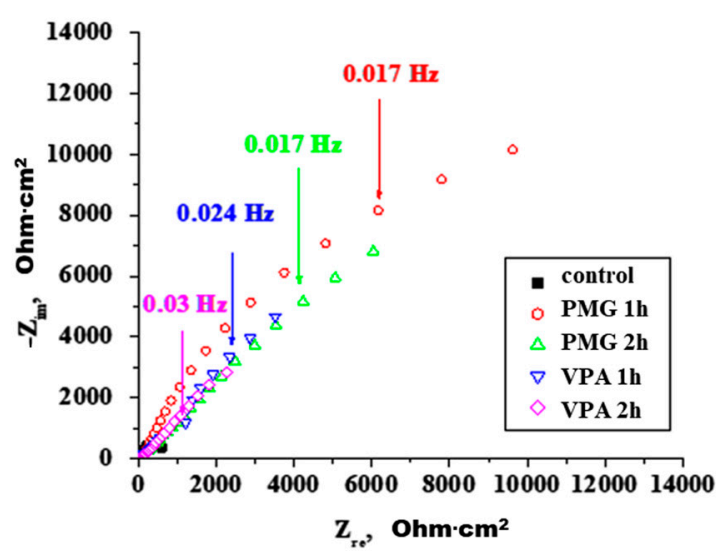

(a)

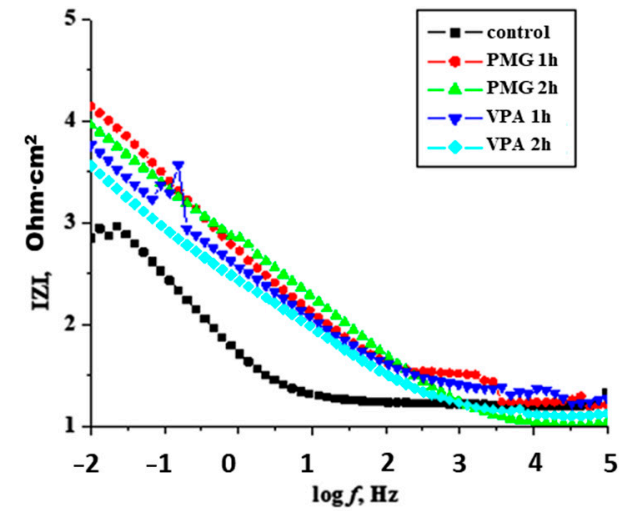

(b)

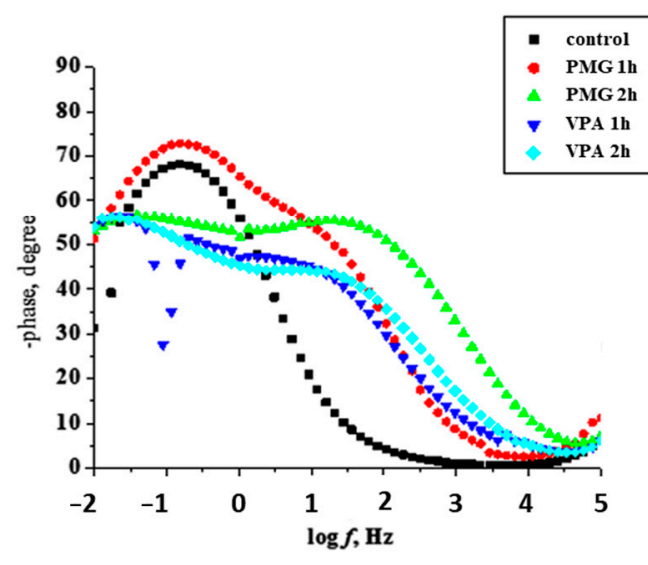

(c)

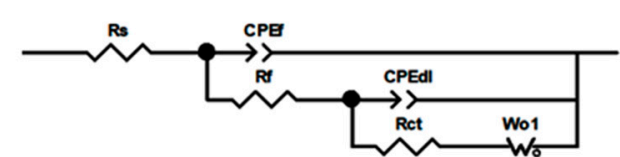

(d)

Figure 3. (a) Complex plane Nyquist plots, (b) Bode plots the logarithm of the impedance modulus I ZI, (c) phase angle as a function of the logarithm of the frequency $f$ for iron immersed for $1 \mathrm{~h}$ in $3.5 \% \mathrm{NaCl}$ solutions in the presence of inhibitors and (d) electrical equivalent circuit.

Figure 3 a reveals an increase in the capacitive arc radius by adding inhibitors in the solution. The PMG and VPA present a similar form for capacitive arcs. The arcs are nonideal semi-circles due to the frequency dispersion caused by the corrosion of metal and/or adsorption on inhibitors at the metal surface [45]. The kinetic parameters were obtained by fitting with an appropriate equivalent circuit (Figure $3 \mathrm{~d}$ ) and the resulting parameters are summarized in Table 2 . The electrical circuit used consists of solution resistance- $R_{s}$, film resistance $-R_{f}$, charge transfer resistance $-R_{c t}$, and a diffusional element $W$ (Warburg element). The capacitive elements used, $\mathrm{CPE}_{\mathrm{f}}$ and $\mathrm{CPE}_{\mathrm{dl}}$, represent the constant phase element of the film and the electrical double layer, respectively.

In the Bode phase plots (Figure 3c), two-time constants are present. The loop observed at low frequency (LF) was attributed to the mass transfer and that at the intermediate frequency was linked to the $\mathrm{R}_{\mathrm{ct}}$ and double layer capacitance, as was reported by other authors [46]. The incomplete capacitive loop observed at high frequency is due to the nonhomogeneous current distribution on the electrode surface. In the intermediate frequency region, the highest value for the phase angle is observed for PMG at $2 \mathrm{~h}\left(\approx 60^{\circ}\right)$. The phase angle, in the case of PMG, shows an increasing tendency with the increase of immersion time. For VPA, the phase angle values are lower and remain almost constant with the increase of immersion time. In the presence of inhibitors, the charge transfer resistance $\left(\mathrm{R}_{\mathrm{ct}}\right)$ increases and the double-layer capacitance $\left(C_{d l}\right)$ decreases as a result of the adsorption of the organic molecules at metal surfaces [47]. Instead of a pure capacitance, a CPE element was used. The CPE represents the deviation from ideal dielectric behavior due to 
surface heterogeneity. This element consists of two elements, the exponent (CPE-P) and the pseudocapacitance (CPE-T). The capacitance can be calculated with Equation (8) [48]:

$$
Z_{C P E}=\frac{1}{T(J \cdot \omega)^{\phi}}
$$

where $0<\varphi<1$ describes the deformation of the circle in the complex plane and is a constant. If $\varphi=1, \mathrm{CPE}$ becomes a perfect capacitor. $\omega$ is the angular frequencies (in rad $\cdot \mathrm{s}^{-1}$, with $\omega=2 \pi \cdot f), f$ is the frequency (in $\mathrm{Hz}$ ).

The $\mathrm{T}$ parameter is proportional to the capacity of the double layer, as shown in Equation (9):

$$
T=C_{d s}^{\varphi}\left(R_{s}^{-1}+A\right)^{1-\varphi}
$$

where $C_{d s}^{\varphi}=$ capacity of the double layer, in $\mathrm{F} ; R_{S}=$ solution resistance, in $\Omega ; A=$ electrode surface area, in $\mathrm{cm}^{2}$.

The best fits obtained by modeling EIS data with equivalent electrical circuit presented in Figure $3 c$ are presented in Table 2.

Table 2 shows that the $R_{c t}$ and $C_{d l}$ evolve in time as the composition of the inhibitor layer changes. The results show a higher resistance $R_{f}$ value for PMG both at $1 \mathrm{~h}$ and $2 \mathrm{~h}$. The inhibitor VPA presents lower values of resistance $R_{f}$ both at $1 \mathrm{~h}$ and $2 \mathrm{~h}$. This suggests that PMG adsorb and form a compact layer on the metal surface. This compact layer contains a low number of ionically conducting paths and presents a higher corrosion performance. The VPA layer seems to be more porous. The high number of ionically conducting paths present in the VPA layer will allow corrosion species to be present on the metal surface. The $\mathrm{CPE}_{\mathrm{f}}$ values decrease with immersion time. The decrease is associated with the adsorbed layer, which can become thicker, or to the decrease in the dielectric constant of the protective layer (Equation (10)).

$$
C=\frac{\varepsilon_{r} \varepsilon_{0} A}{d}
$$

where $C$ represents the capacitance, $\varepsilon_{0}$-void permittivity, $8.8 \times 10^{-12} \mathrm{~F} \cdot \mathrm{m}^{-1}, \varepsilon_{r}$ - dielectric constant of the protective layer, $A$-area in $\mathrm{cm}^{2}$, and $d$-thickness of the coating (layer).

In all determinations, $\mathrm{CPR}_{\mathrm{f}}$ decreased in time, as the protective layer evolved. The $\mathrm{CPE}_{\mathrm{f}}$ in the case of VPA is lower than in the presence of PMG. This means a thicker protective layer formed by the VPA inhibitor, but corroborated with the $R_{f}$ value, the layer is porous.

The lower $R_{c t}$ value obtained for VPA suggests a lower ability of this acid to link to the metal surface and to form a porous layer that in time can become incomplete and easy for corrosive species to penetrate. These results are sustained by adsorption data, CP data, and ATR. The addition of inhibitors to the solution also modifies the double-layer capacitance $C_{d l}$. A lower value of $C P E_{d l}$ means good adherence. Higher $R_{c t}$ and lower $C_{d l}$ values are obtained for PMG, indicating the formation of a thicker and compact layer. The bonding through $\mathrm{P}-\mathrm{O}$ ionic species and a nitrogen atom on the iron surface in a stronger manner leads to a more efficient packing on the surface (confirmed also by ATR data). Even thought VPA has a strong tendency to utilize the $\mathrm{P}-\mathrm{OH}, \mathrm{P}=\mathrm{O}$, and $\mathrm{C}=\mathrm{C}$ moieties to form a thicker layer on the metal surface, the majority of bonds are weaker (P-OH-O-Fe) (confirmed also by ATR data). The $\mathrm{CPE}_{\mathrm{dl}}-\mathrm{P}$ value gives a measure of the deviation from ideal capacitive behavior, which depends strongly on the state of the surface [48]. The obtained $\mathrm{CPE}_{\mathrm{dl}}-\mathrm{P}$ exponents are ranging between 0.42 and 0.74 , which are the values that indicate the presence of a non-homogenous surface, especially at prolonged immersion time $[49,50]$. The calculated time constant $\tau_{d}\left(\tau_{d}=C_{d l} \cdot R_{c t}\right)$ suggests some differences in the adsorption process with immersion time. The adsorption process becomes slower for higher $\tau_{d}$. The results obtained for the time constants show that the lowest value is obtained for the PMG sample at $3.14 \mathrm{~s}$ and $2.69 \mathrm{~s}$ for $1 \mathrm{~h}$ and $2 \mathrm{~h}$, respectively comparing with $6.23 \mathrm{~s}$ and $3.35 \mathrm{~s}$ at $1 \mathrm{~h}$ and $2 \mathrm{~h}$, respectively for the VPA sample. If the layer presents a 
higher number of pores and is thin, the corrosion process takes place deeper within the pores, close to the metal surface. The displacement of the diffusion-controlled process will take place in this case to lower frequencies. The displacement is more evident with the increase of immersion time. The shifts to lower frequencies are more evident in the case of VPA. In time, the layer becomes more porous, and diffusion phenomena appear. The value of the Warburg impedance coefficient, $\mathrm{W}-\mathrm{R}$, represents the resistance originating from the diffusion process through the pores within the corrosion layer. The Warburg impedance was necessary for the fitting of the experimental data process only at prolonged immersion time for both inhibitors. This shows the appearance of resistance due to the diffusion processes as the porosity of films increases over time. The inhibition efficiency (IE) in and surface coverage was calculated from the values of charge transfer resistance by Equations (11) and (12).

$$
\begin{gathered}
I E=\frac{R_{c t}^{i n h}-R_{c t}^{c o n t r o l}}{R_{c t}^{i n h}} \times 100 \\
\Theta=\frac{I E}{100}
\end{gathered}
$$

where $R_{c t}{ }^{i n h}$ is the charge transfer resistance for the electrode in the presence of an inhibitor; $R_{c t}{ }^{c o n t r o l}$ is the charge transfer resistance for the electrode in solution without an inhibitor.

The percentage of inhibitory efficiency calculated based on EIS data reveal the same tendency observed in the values from the polarization data. The highest results are for PMG (90-95\%) and they are a little lower for VPA (75-90\%). The IE is comparable with the values reported for other phosphate layers [51,52].

\subsection{Adsorption Isotherm}

The adsorption isotherm is considered a good method to express quantitatively the adsorption process and interactions between the adsorbed inhibitor molecules and metal surface and is a helpful factor in the understanding of the inhibition mechanism [53]. The most appropriate adsorption mode can be determined from the covered fraction of the metal surface by adsorbed molecules $(\theta)$. The values can be determined with Equation (12) from impedance EIS or CP data. Figure S1 (Supplementary Materials) shows the plots for $(C / \theta)$ in the function of $C_{\text {inhibitor }}$. where $\theta$ is the surface coverage, $C=C_{\text {inhibitor }}$ is the inhibitor concentration, and $K_{a d s}$ is the adsorption equilibrium constant.

The linear dependence and the value of the regression coefficient $\left(R^{2}=0.998\right)$ show that the Langmuir adsorption isotherm is the best-fit isotherm, as shown in Equation (13).

$$
\frac{C}{\theta}=\frac{1}{K_{a d s}}+C
$$

These inhibitors obey Langmuir adsorption isotherm as other phosphonic acids on the metal surface [54]. The $K_{a d s}$ represents the adsorption strength between the inhibitor and metal surface. More efficient adsorption implies a larger value for $K_{a d s}$ and a smaller value for the dimensionless separation factor, $R_{L}$ (Equation (14)) [55].

$$
R_{L}=\frac{1}{1+K_{a d s} C}
$$

The highest $K_{a d s}$ value was obtained for PMG. The calculated values of $R_{L}$ for the inhibitors (Table 3 ) are less than unity. The values indicate a favorable adsorption process. The free energy of adsorption $\left(\Delta G^{\circ}\right.$ ads $)$ was calculated using Equation (15):

$$
\Delta G^{\circ}{ }_{a d s}=-R T \operatorname{Ln}\left(55.5 K_{a d s}\right)
$$

where $R$ is the universal gas constant $\left(8.314 \mathrm{~J} \cdot \mathrm{mol}^{-1} \cdot \mathrm{K}^{-1}\right)$ and $T$ is the absolute temperature in Kelvin, $K_{a d s}$ is the adsorption equilibrium constant, $\Delta G^{\circ}$ ads is the standard free energy of adsorption, and 55.5 is the concentration of water in the solution in $\mathrm{mol} \cdot \mathrm{dm}^{-3}$. 
Table 2. Values of the electric circuit elements for the electrodes after 1 and $2 \mathrm{~h}$ of immersion.

\begin{tabular}{|c|c|c|c|c|c|c|c|c|c|c|}
\hline Sample/*SD & Chi-Sqr & $\mathrm{R}_{\mathrm{s}}, \Omega \cdot \mathrm{cm}^{2}$ & $\begin{array}{c}\text { CPE f, } \\
\mathrm{F} / \mathrm{cm}^{2} / \mathrm{s} \cdot \varphi^{-1}\end{array}$ & $\begin{array}{c}\text { CPE-P f, } \\
\varphi\end{array}$ & $\begin{array}{c}R_{\mathrm{f}} \\
\Omega \cdot \mathrm{cm}^{2}\end{array}$ & $\begin{array}{c}\mathrm{CPE}_{\mathrm{dl}-} \mathrm{T} \\
\mathrm{F} / \mathrm{cm}^{2} / \mathrm{s} \cdot \varphi^{-1}\end{array}$ & $\mathrm{CPE}_{\mathrm{d} 1}-\mathrm{P}, \varphi$ & $\begin{array}{r}R_{\mathrm{ct}} \\
\Omega \cdot \mathrm{cm}^{2}\end{array}$ & $\begin{array}{r}W-\mathrm{R}, \\
\Omega \cdot \mathrm{cm}^{2}\end{array}$ & $\begin{array}{l}I E, \\
\%\end{array}$ \\
\hline $\mathrm{Fe}$ & $1.00 \times 10^{-3}$ & $16.64 \pm 1.23$ & $\begin{array}{c}1.60 \times 10^{-3} \pm 0.29 \times \\
10^{-5}\end{array}$ & $0.72 \pm 0.04$ & $19.72 \pm 2.32$ & $\begin{array}{c}2.19 \times 10^{-3} \pm 2.76 \times \\
10^{-4}\end{array}$ & $0.78 \pm 0.03$ & $688 \pm 31$ & - & - \\
\hline PMG $2 \mathrm{~h}$ & $1.75 \times 10^{-4}$ & $2.489 \pm 0.19$ & $\begin{array}{c}1.87 \times 10^{-14} \pm 3.01 \times \\
10^{-15}\end{array}$ & $0.89 \pm 0.02$ & $36.67 \pm 4.23$ & $\begin{array}{c}1.94 \times 10^{-4} \pm 0.35 \times \\
10^{-5}\end{array}$ & $0.59 \pm 0.03$ & $13,890 \pm 223$ & $0.13 \pm 0.91$ & $95.05 \pm 0.07$ \\
\hline VPA $1 \mathrm{~h}$ & $4.18 \times 10^{-3}$ & $1.67 \pm 0.03$ & $\begin{array}{c}4.85 \times 10^{-9} \pm 2.54 \times \\
10^{-10}\end{array}$ & $0.69 \pm 0.04$ & $34.19 \pm 4.12$ & $\begin{array}{c}8.25 \times 10^{-4} \pm 0.57 \times \\
10^{-5}\end{array}$ & $0.65 \pm 0.04$ & $7056 \pm 92$ & - & $90.25 \pm 0.03$ \\
\hline VPA $2 \mathrm{~h}$ & $1.03 \times 10^{-3}$ & $1.976 \pm 1.06$ & $\begin{array}{c}4.32 \times 10^{-14} \pm 1.27 \times \\
10^{-15}\end{array}$ & $0.45 \pm 0.03$ & $22.104 \pm 1.75$ & $\begin{array}{c}1.38 \times 10^{-3} \pm 0.87 \times \\
10^{-5}\end{array}$ & $0.42 \pm 0.07$ & $2829 \pm 86$ & $324.2 \pm 0.41$ & $75.68 \pm 0.23$ \\
\hline
\end{tabular}

*SD—standard deviation. 
Table 3. Adsorption parameters $\left(K_{a d s}, R_{L}\right.$ and $\Delta G^{\circ}$ ads $)$ for PMG and VPA.

\begin{tabular}{ccc}
\hline Inhibitor & PMG & VPA \\
\hline$K_{a d s}, \mathrm{~mol}^{-1}$ & 34676.66 & 22888.95 \\
$\Delta G^{\circ}{ }_{a d s}, \mathrm{~J} /$ mole & -35851.75 & -34821.81 \\
$R_{L}$ & 0.13 & 0.18 \\
\hline
\end{tabular}

Generally, a value of $\Delta G^{\circ}$ ads around $-20 \mathrm{~kJ} \cdot \mathrm{mol}^{-1}$ or more positive indicates physisorption, while values around $-40 \mathrm{~kJ} \mathrm{~mol}^{-1}$ or more negative point to a chemisorptions [56]. The negative $\Delta G^{\circ}$ ads values obtained and high values of $K_{\text {ads }}$ (Table 3) show that in the presence of these inhibitors, the adsorption process is spontaneous. In addition, covalent/electrostatic interaction exists, and the degree in surface coverage was developed according to the Langmuir adsorption isotherm.

The value is higher for PMG. The ATR spectra reveal that the phosphonic group undergoes deprotonation upon adsorption, which is more evident in the first hour of immersion. With the increase of immersion time, there is a more compact adsorbed layer due to a bidentate linkage. The absence of a phosphonate peak assigned to P-O stretching motions $\left(v_{\mathrm{P}-\mathrm{O}}\right)$ indicates the absence of uncomplexed P-O. This observation is corroborated by the higher $\mathrm{R}_{\mathrm{ct}}$ value obtained at a higher immersion time. In consequence, it is possible to assume that the interaction between the amine group and Fe surface brings the $\mathrm{PO}_{3}{ }^{2-}$ groups closer to the metal surface, and the disappearance of a band attributed to asymmetric bending of the quaternary ammonium ion proves that the carboxylate and nitrogen atom is also involved in complex formation. This is sustained by the value of $\Delta G^{\circ}{ }_{a d s}$, which is a value that indicates combined physisorption and chemisorptions [57].

The capacity of VPA to interact to the iron surface through the double bond, $\mathrm{P}=\mathrm{O}$, and $\mathrm{P}-\mathrm{OH}$ groups are responsible for a better surface immobilization, as confirmed by ATR and $\Delta G^{\circ}$ ads. The obtained value around $23 \mathrm{~kJ} \cdot \mathrm{mol}^{-1}$ suggests for the VPA an adsorption predominant by physisorption. The bond associated with physisorption and/or desorption is weaker and the occurrence of larger pores takes place with the increase of immersion time.

\subsection{Surface Analysis}

The surface of the carbon steel electrode was achieved at different immersion times between 0.5 and $12 \mathrm{~h}$ in $3 \% \mathrm{NaCl}$ solution without and with inhibitors. Figure S2 (Supplementary Materials) shows all specimens for comparison.

The optical images show that the carbon steel surface was covered substantially by corrosion products in the case of iron immersed only in $\mathrm{NaCl}$ solution at $\mathrm{pH}=2.3$. Comparing the surface of metal immersed in $\mathrm{NaCl}$ solution with and without inhibitor, it is obvious that a protective layer on the metal surface was formed in the presence of inhibitors. The formed layer presents a different pattern, depending on the inhibitor and immersion time. The surface formed in the presence of the VPA inhibitor seems less smooth and thinner, suggesting the formation of a porous or less compact film on the metal surface. The surface roughness influences the carbon steel's corrosion behavior. The surface measurements by optical microscope showed an improvement in the surface smoothness in the occurrence of the corrosion inhibitor, as shown in Figure S3 (Supplementary Materials). This is a result of the adsorption of inhibition. The surface roughness Ra parameter (average roughness) was determined from the arithmetic average of the gray level [58].

The arithmetic average of the gray level can be expressed as shown in Equation (16)):

$$
\mathrm{Ra}=\left(\sum(|\mathrm{g} 1-\mathrm{gm}|+|\mathrm{g} 2-\mathrm{gm}|+\ldots . .+|\mathrm{gn}-\mathrm{gm}|) / \mathrm{n}\right.
$$

where $g 1, \ldots$ and gn are the gray level values of a surface image along one line.

The mean of the gray values (gm) is determined as shown in Equation (17):

$$
\mathrm{gm}=\left(\sum(\mathrm{g} 1+\mathrm{g} 2+\ldots . .+\mathrm{gn})\right) / \mathrm{n}
$$


The values of the average roughness $(\mathrm{Ra})$ for the carbon steel surface before and after electrochemical measurements are for PMG: $9.14 \mu \mathrm{m}$ at $0.5 \mathrm{~h}, 11.02 \mu \mathrm{m}$ at $1 \mathrm{~h}$, and $14.87 \mu \mathrm{m}$ at $2 \mathrm{~h}$. For VPA, they are $18.14 \mu \mathrm{m}$ at $0.5 \mathrm{~h}, 16.59 \mu \mathrm{m}$ at $1 \mathrm{~h}$, and $27.33 \mathrm{~m}$ at $2 \mathrm{~h}$. For Fe corroded in $3 \% \mathrm{NaCl}$ solution without inhibitor, the surface roughness was higher due to the corrosion process: $69.93 \mu \mathrm{m}$ at $0.5 \mathrm{~h}, 91.08 \mu \mathrm{m}$ at $1 \mathrm{~h}$, and $108.17 \mu \mathrm{m}$ at $2 \mathrm{~h}$. The increase of smoothness in the case of PMG reveals a better performance (Figure S3a from Supplementary Materials). ATR studies also supported the presence of the adsorbed inhibitor on the C-steel surface. An increase in charge transfer resistance $\left(\mathrm{R}_{\mathrm{ct}}\right)$ values with decreasing roughness for mild steel tested in ammonium chloride $\left(\mathrm{NH}_{4} \mathrm{Cl}\right)$ solution was reported also [59]. The negative value of the adsorption energy for both inhibitors proved that the adsorption process takes place spontaneously. The order of binding energy (PMG > VPA) confirmed the order of the experimental data.

\subsection{Theoretical Chemical Calculations}

Stereochemical characteristics of a molecule can affect its stability and reactivity to other molecules. In this context, the global reactivity descriptors deliver relevant information about compound stability and reactivity. All electronic parameters were calculated based on full optimized geometry (Table 4 and Figure 4). The frontier molecular orbitals, LUMO and HOMO, are valued as key indicators for the chemical reactivity and stability of a molecule. The electron-donating capacity of a molecule to a proper acceptor with empty molecular orbitals (e.g., metal) is expressed by $E_{\mathrm{HOMO}}$, while the electron-accepting ability is indicated by $E_{\mathrm{LUMO}}$. The influences of these descriptors on the ability of the anticorrosive compounds to react with a substrate are listed in Table 4.

Table 4. The calculated electronic properties of the studied compounds.

\begin{tabular}{|c|c|c|c|c|c|}
\hline Descriptors & & VPA & VPA $^{2-}$ & PMG & $\mathrm{PMG}^{3-}$ \\
\hline$E_{\mathrm{HOMO}}$ & \multirow{8}{*}{$\mathrm{eV}$} & -7.756 & -8.172 & -6.373 & -12.980 \\
\hline$E_{\mathrm{LUMO}}$ & & -0.690 & -2.622 & -0.577 & -7.665 \\
\hline Ionization potential, IP & & 7.756 & 8.172 & 6.373 & 12.980 \\
\hline Electron affinity, $E A$ & & 0.690 & 2.622 & 0.577 & 7.665 \\
\hline Energy gap, $\Delta E$ & & 7.066 & 5.550 & 5.796 & 5.315 \\
\hline Chemical hardness, $\eta$ & & 3.533 & 2.775 & 2.898 & 2.657 \\
\hline Electrophilic index, $\omega$ & & 2.524 & 5.248 & 2.083 & 20.050 \\
\hline Softness, $\sigma$ & & 0.283 & 0.360 & 0.345 & 0.376 \\
\hline
\end{tabular}

In addition to the HOMO and LUMO frontiers orbitals, the energy gap is also an essential parameter to explain the activity of an anticorrosive compound. The low value of the energy gap for PMG compared to VPA indicates that it absorbs quickly because a small gap implies less excitation energy to remove electrons from the last occupied orbital. In addition, the dipole moment is an important electronic parameter and has a significant role in corrosion inhibition [60]. The higher value of the dipole moment for PMG (5.2866) comparing with the value of the dipole moment for VPA (1.6265) probably increases the adsorption between PMG and the metal surface [61]. As can be seen in Table 4, the lower values of $E_{\mathrm{LUMO}}$ show that PMG, followed by VPA, can easily receive free electrons from the metal. Moreover, PMG has the highest $E_{\mathrm{HOMO}}$ value as compared to VPA. For PMG, the HOMO orbitals appear mainly in the proximity of nitrogen and carbon atoms bound to nitrogen, and of oxygen atoms $(=\mathrm{O})$ bond to phosphorus atoms, while for VPA, they occur in the vicinity of oxygen atoms and the vinyl unit (Figure 4). The unoccupied d orbital of the Fe atom can accept electrons from PMG and VPA to form a coordination bond. PMG and VPA can also accept electrons from the iron atom with its anti-bonding orbitals to form a back-donating bond. These atomic sites assist the adsorption of the PMG and VPA on the metal surface. Additionally, the potential $(\mu)$, electronic hardness $(\eta)$, electrophilicity index $(\omega)$, and global softness $(\sigma)$ parameters as complementary information for chemical 
reactivity of both molecules were evaluated. The concordance with the experimental information was found to be satisfactory.
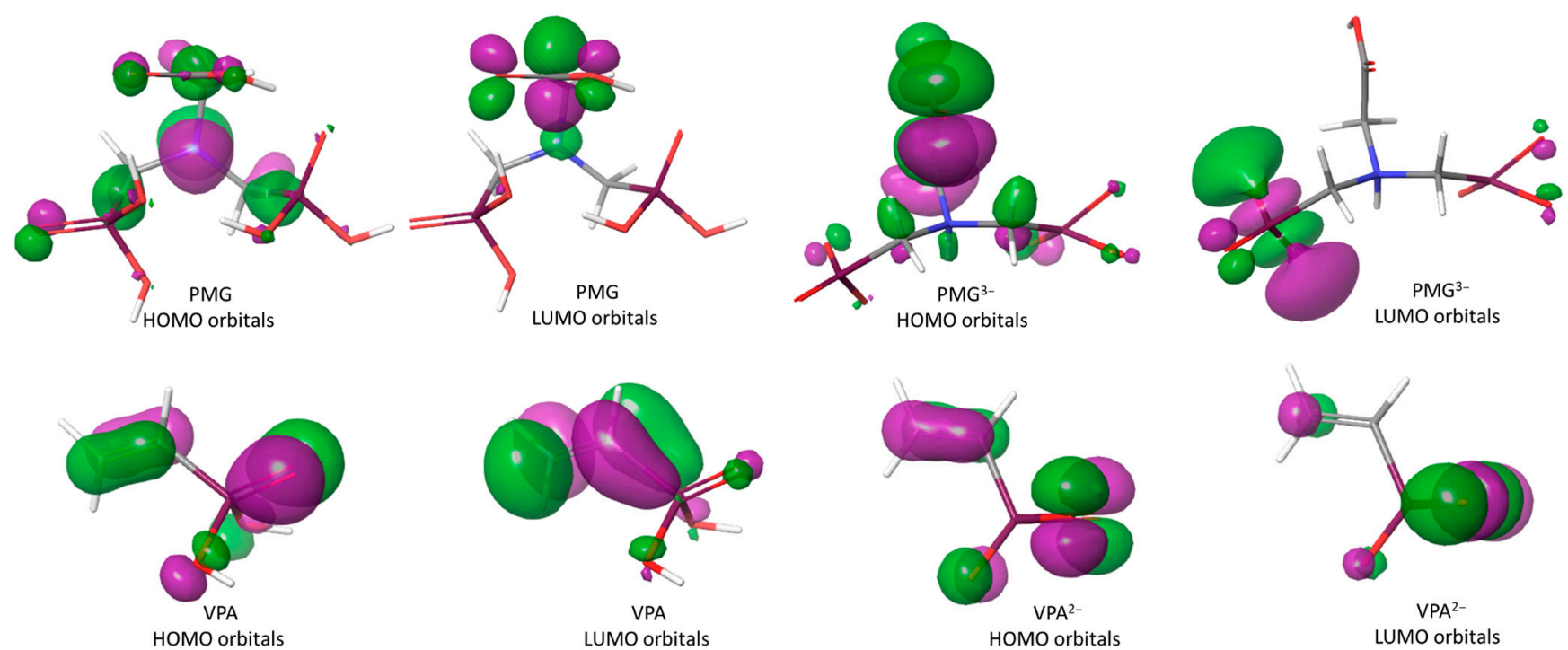

Figure 4. Highest occupied molecular orbital (HOMO) and the lowest unoccupied molecular orbital (LUMO) of PMG, $\mathrm{PMG}^{3-}$, VPA, and $\mathrm{VPA}^{2-}$ compounds.

The same quantum chemical calculations and the same protocol have been successfully applied for the deprotonated species (Table 4 and Table S1 from Supplementary Materials). The $\mathrm{PMG}^{3-}$ has the lowest of the energy gap and the highest softness $(\sigma)$. The electrophilicity index $(\omega)$ also indicates the electron-accepting ability of a compound surface [62]. The value for this descriptor confirms that $\mathrm{PMG}^{3-}$ has the highest ability to accept electrons among the studied compounds. These results lead to the conclusion that the adsorption between $\mathrm{PMG}^{3-}$ and the metal surface is in all likelihood the highest. This conclusion for $\mathrm{PMG}^{3-}$ anticorrosion efficiency is also supported by the electrostatic potential [63], which is pictured in Figure S4. The red color indicates the most negative region while the blue color stands for the most positive region in $\mathrm{PMG}^{3-}$ (Figure S4).

The region with a deficiency of electrons (red) is concentrated around the oxygen atoms from $\mathrm{PO}_{3}$ groups, which suggests that they represent potential centers of adsorption. The same conclusion emerges by Mulliken charge population analysis (Figure S4). Similar to other investigations [1,2,60-63], our conclusions highlight the importance of theoretical and experimental insight on the corrosion inhibition behavior for different organic compounds.

Thus, the most stable ionic structure is the deprotonated one at both $\mathrm{P}-\mathrm{OH}$ from each $\mathrm{PO}_{3} \mathrm{H}_{2}$ group and with $\mathrm{NH}^{+}$called $\mathrm{PMG}^{3-}$ and for the other $\mathrm{VPA}^{2-}$.

The HOMO-LUMO differences are presented in Table 4. It is observed that for the $\mathrm{PMG}^{4-}$ form $\left(\mathrm{PMG}^{3-}\right.$ with $\mathrm{COOH}$ deprotonated), the HOMO-LUMO difference is very large (Table S1 from Supplementary Materials). So, the mechanism and the discussion of ATR are in accordance with the most stable ionic forms. From all data, it is revealed that the $\mathrm{COOH}$ moiety does not participate in the surface binding.

\subsection{Mechanism of Corrosion Inhibition}

The action of PMG and VPA in saline solution at $\mathrm{pH}=2.3$ reveals that the studied phosphonic acids are capable of inhibiting the corrosion by controlling both the anodic and cathodic reactions. In acidic solutions, the inhibitors may exist as protonated species. These protonated species adsorb on the cathodic sites of the carbon steel and decrease the evolution of hydrogen. The decreases of anodic reaction can be achieved by adsorption on anodic sites occurs through the $\pi$-electrons of a double bond or by the lone pair electrons of nitrogen and oxygen atoms [64]. However, the VPA inhibitory value is slightly lower than the PMG, which may suggest that the nitrogen atom brings an additional contribution to 
the corrosion inhibition in a significant manner. The PMG molecules present in the solution can be in the form of zwitter ions, in neutral form, or protonated. Lone pairs of electrons of the $\mathrm{O}$ and $\mathrm{N}$ atoms agree to a stable interaction with the surface (Fe). Coordination through $\pi$-electrons of $\mathrm{P}=\mathrm{O}$ and lone pairs of electrons to the d-orbitals of the Fe surface takes place as a result from experimental data and is in accordance with computational data. At $\mathrm{pH} \approx 2.3$, a fraction of PMG molecules can have a positive charge as a metal surface that is also positively charged. The repulsive force tends to make adsorption impossible. However, the experimental data show high values of $R_{c t}$ and surface coverage degree. Chloride ions adsorbed on the metal surface will create an excessive negative charge at the metal-solution interfaces, as can be seen in Figure 5.

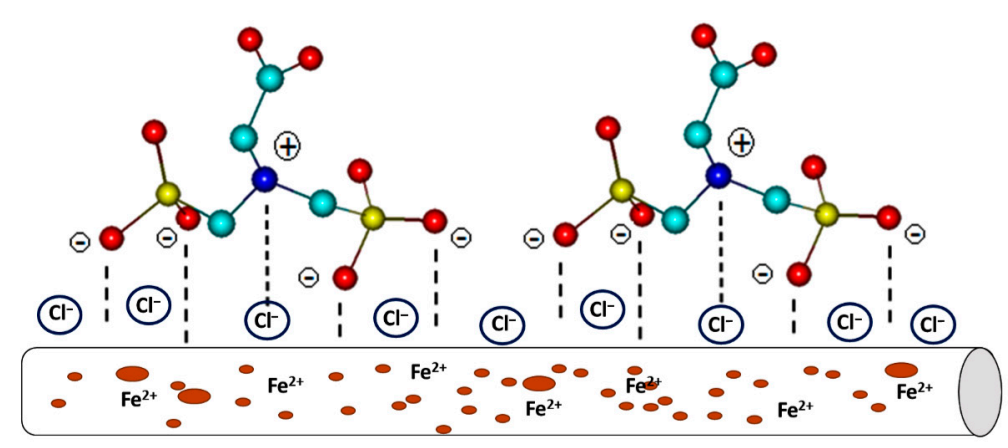

(a)

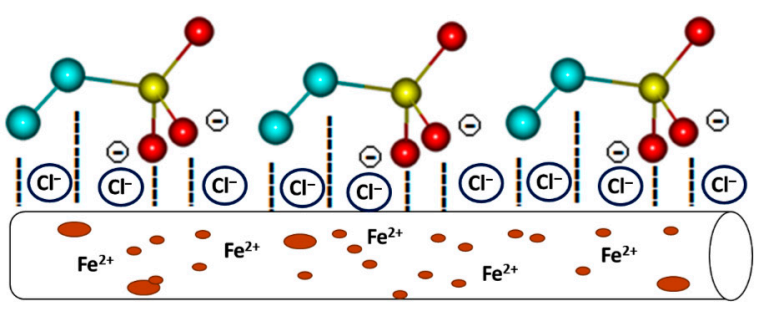

(b)

Figure 5. The possible mechanism of (a) $\mathrm{PMG}^{3-}$ and (b) $\mathrm{VPA}^{2-}$ corrosion protection studies. Color code: yellow-P, red-O, turquoise $-\mathrm{C}$. The hydrogen atoms are omitted for clarity.

As a result, $\mathrm{PMG}^{3-}$ can be easily adsorbed. Chloride ions show a synergic effect. A similar conclusion was reported in the literature $[51,65,66]$. The synergic effect of chlorine ions indicated that a small amount of the PMG inhibitor was capable of inhibiting the corrosion process up to $\approx 97 \%$.

\section{Conclusions}

PMG and VPA were examined to determine their potential to act as a corrosion inhibitor $3 \% \mathrm{NaCl} \mathrm{pH}=2.3$ by polarization, impedance, ATR, and computational analysis. The resulting polarization curves suggest that PMG and VPA act as mixed-type inhibitors. Results evidenced that all inhibitors showed excellent performance (IE more than 85\%). It was shown that PMG exhibits better protection comparing with VPA at the same concentration. The adsorption process follows the Langmuir isotherm, and it indicates combined physisorption and chemisorption. The different self-assembling processes take place at the metal surface, with the increase of immersion time simultaneously difficult to separate (adsorption and reorientation of molecules). The ATR spectra reveal for PMG a bidentate linkage with the $\mathrm{P}-\mathrm{OH}$ and nitrogen atom involved in complex formation on the metal surface. This is sustained by the value of $\Delta G^{\circ}$ ads, which indicates combined physisorption and chemisorption for PMG. The capacity of VPA to interact to the iron surface through the double bond, $\mathrm{P}=\mathrm{O}$, and $\mathrm{P}-\mathrm{OH}$ groups are responsible for immobilization, as confirmed by ATR and $\Delta G^{\circ}$ ads, with predominant physisorption. The synergic effect of chlorine ions indicated that a small amount of the PMG inhibitor was capable of inhibiting the corrosion process up to $\approx 97 \%$. The experimental data and the results of the theoretical calculations are strongly correlated. The calculated values for the $E_{\mathrm{LUMO}}$ and $E_{\mathrm{HOMO}}$, gap energy $(\Delta E)$, dipole moment $(\mu)$, electronic hardness $(\eta)$, global softness $(\sigma)$, electrophilic index $(\omega)$, and the electronic potential map support the experimental data which indicate that PMG as $\mathrm{PMG}^{3-}$ has the best potential anticorrosion efficiency. These results gained in the present study are very useful and can be a basis in the development of more feasible efficient corrosion inhibitors. Molecular modeling studies supported well the experimental data. 
Supplementary Materials: The following are available: Figure S1. The isotherm Langmuir plots for tested inhibitors, Figure S2. Optical images for unprotected (control) and protected (by the PMG and VPA) carbon steel specimens, Figure S3. The histogram of surface roughness (a) for PMG and (b) VPA after exposure different time to $\mathrm{NaCl} 3 \%$ solution at $\mathrm{pH}=2.3$, Figure S4. The electrostatic potential and Mulliken charge distribution in $\mathrm{PMG}^{3-}$, Table S1. The calculated electronic properties of the deprotonated compounds.

Author Contributions: Conceptualization, A.V., N.P., L.C. and A.B.; Investigation, A.V., B.M., G.I., N.P., L.C. and A.B.; Methodology, L.C. and A.B.; Validation, A.V., N.P.; Visualization, L.C.; Writingoriginal draft, A.V., N.P., G.I., B.M., L.C. and A.B.; Writing-review and editing, A.V., L.C. and A.B. All authors discussed the outcomes and commented on the paper. All authors contributed equally to this work. All authors have read and agreed to the published version of the manuscript.

Funding: This work was supported by Program no. 1 and 2, from the "Coriolan Dragulescu" Institute of Chemistry Timisoara, Romania. The APC was supported by the authors.

Data Availability Statement: The data presented in this study are available on request from the corresponding author.

Acknowledgments: The authors would like to thank Ramona Curpan ("Coriolan Dragulescu" Institute of Chemistry Timisoara) for providing access to Schrödinger software, and to Mircea and Maria Mracec for access to the HyperChem 7.52.

Conflicts of Interest: The authors declare no conflict of interest.

\section{References}

1. Uzma, N.; Zareen, A.; Naveed, Z.A.; Faiz, U.S. Experimental and theoretical insights into the corrosion inhibition activity of novel Schiff bases for aluminum alloy in acidic medium. RSC Adv. 2019, 9, 36455-36470. [CrossRef]

2. Uzma, N.; Zareen, A.; Naveed, K.J.; Muhammad, A.A.; Sehrish, K.; Tehmeena, M.B.; Asma, S.; Faroha, L.; Rizwan, H.; Faiz, U.S. Biferrocenyl Schiff bases as efficient corrosion inhibitors for an aluminium alloy in $\mathrm{HCl}$ solution: A combined experimental and theoretical study. RSC Adv. 2020, 10, 7585-7599. [CrossRef]

3. Obot, I.; Madhankumar, A.; Umoren, S.A.; Gasem, Z.M. Surface protection of mild steel using benzimidazole derivatives: Experimental and theoretical approach. J. Adhes. Sci. Technol. 2015, 29, 2130-2152. [CrossRef]

4. Kovačević, N.; Kokalj, A. Analysis of molecular electronic structure of imidazole-and benzimidazole- based inhibitors: A simple recipe for qualitative estimation of chemical hardness. Corr. Sci. 2011, 53, 909-921. [CrossRef]

5. Visa, A.; Maranescu, B.; Bucur, A.; Iliescu, S.; Demadis, K.D. Synthesis and characterization of a novel phosphonate metal organic framework starting from copper salts. Phosphorus Sulfur Silicon Relat. Elem. 2014, 189, 630-639. [CrossRef]

6. Visa, A.; Mracec, M.; Maranescu, B.; Maranescu, V.; Ilia, G.; Popa, A. Structure simulation into a lamellar supramolecular network and calculation of the metal ions/ligands ratio. Chem. Cent. J. 2012, 6, 91. [CrossRef]

7. Maranescu, B.; Plesu, N.; Visa, A. Phosphonic acid vs phosphonate metal organic framework influence on mild steel corrosion protection. Appl. Surface Sci. 2019, 497, 143734. [CrossRef]

8. Maranescu, B.; Lupa, L.; Tara Lunga Mihali, M.; Plesu, N.; Maranescu, V.; Visa, A. The Corrosion Inhibitor Behavior of Iron in Saline Solution by the Action of Magnesium Carboxyphosphonate. Pure Appl. Chem. 2018, 90, 1713-1722. [CrossRef]

9. Attavar, S.; Diwekar, M.; Linford, M.R.; Davis, M.A.; Blair, S. Passivation of aluminum with alkyl phosphonic acids for biochip applications. Appl. Surf. Sci. 2010, 256, 7146-7150. [CrossRef]

10. Hoque, E.; DeRose, J.A.; Kulik, G.; Hoffmann, P.; Mathieu, H.J.; Bhushan, B. Alkylphosphonate modified aluminum oxide surfaces. J. Phys. Chem. B 2006, 110, 10855-10861. [CrossRef]

11. Prathipa, V.; Raja, A.S. Review on the Assessment of Amino Acids Used As Corrosion Inhibitor of Metals and Alloys. J. Chem. Biol. Phys. Sci. 2017, 5, 1585-1619.

12. Popa, S.; Iliescu, S.; Ilia, G.; Plesu, N.; Popa, A.; Visa, A.; Macarie, L. Solid polymer electrolytes based on phosphorus containing polymers for lithium polymer batteries. Eur. Polym. J. 2017, 94, 286-298. [CrossRef]

13. Iliescu, S.; Avram, E.; Pascariu, A.; Plesu, N.; Popa, A.; Ilia, G. New technique for the synthesis of polyphosphoesters. Macromol. Res. 2011, 19, 1186-1191. [CrossRef]

14. Iliescu, S.; Ilia, G.; Pascariu, A.; Plesu, N. Organic solvent-free synthesis of phosphorus-containing polymers. Pure Appl. Chem. 2007, 79, 1879-1884. [CrossRef]

15. Shahzad, K.; Fayyad, E.M.; Nawaz, M.; Fayyaz, O.; Shakoor, R.A.; Hassan, M.K.; Umer, M.A.; Baig, M.N.; Raza, A.; Abdullah, A.M. Corrosion and Heat Treatment Study of Electroless NiP-Ti Nanocomposite Coatings Deposited on HSLA Steel. Nanomaterials 2020, 10, 1932. [CrossRef] [PubMed]

16. Yadav, M.; Sharma, D.; Kumar, S.; Bahadur, I.; Ebenso, E.E. Electrochemical and theoretical studies on amino phosphonates as efficient corrosion inhibitor for N80 steel in hydrochloric acid solution. Int. J. Electrochem. Sci. 2014, 9, 6580-6593. 
17. Lv, K.; Yang, C.-T.; Liu, Y.; Hu, S.; Wang, X.-L. The Hydrolytic Stability and Degradation Mechanism of a Hierarchically Porous Metal Alkylphosphonate Framework. Nanomaterials 2018, 8, 166. [CrossRef] [PubMed]

18. Kálmán, E.; Várhegyi, B.; Bakó, I.; Felhosi, I.; Kármán, F.H.; Shaban, A. Corrosion inhibition by 1-hydroxy-ethane-1,1-diphosphonic acid. An electrochemical impedance spectroscopy study. J. Electrochem. Soc. 1994, 141, 3357-3360. [CrossRef]

19. Demadis, D. Chemistry of organophosphonate scale inhibitors. Part 4: Stability of amino-tris-(methylene phosphonate) towards degradation by oxidizing biocides. Phosphorus Sulfur Silicon Relat. Elem. 2006, 181, 167-176. [CrossRef]

20. Petric, M.; Crisan, L.; Crisan, M.; Micle, A.; Maranescu, B.; Ilia, G. Synthesis and QSRR Study for a Series of Phosphoramidic Acid Derivatives. Heteroat. Chem. 2013, 24, 138-145. [CrossRef]

21. Moschona, A.; Plesu, N.; Mezei, G.; Thomas, A.G.; Demadis, K.D. Corrosion protection of carbon steel by tetraphosphonates of systematically different molecular size. Corros. Sci. 2018, 145, 135-150. [CrossRef]

22. Choi, D.-J.; You, S.-J.; Kim, J.-G. Development of an environmentally safe corrosion, scale, and microorganism inhibitor for open recirculating cooling systems. Mater. Sci. Eng. A 2002, 335, 228-235. [CrossRef]

23. Tsirulnikova, N.V.; Bolt, Y.V.; Dernovaya, E.S.; Driker, B.N.; Fetisova, T.S. Creation and study of formulations as inhibitors of metal corrosion and scaling for stabilization water treatment in water utilization systems (a review). Int. J. Corros. Scale Inhib. 2016, 5, 66-86. [CrossRef]

24. Kavipriya, K.; Sathiyabama, J.; Rajendran, S.; Nagalakshmi, R. The inhibitive effect of diethylenetriaminepentamethylenephosphonic acid on the corrosion of carbon steel in sea water. Eur. Chem. Bull. 2013, 2, 423-429. [CrossRef]

25. Labjar, N.; Lebrini, M.; Bentiss, F.; Chihib, N.-E.; Hajjaji, S.E.; Jama, C. Corrosion inhibition of carbon steel and antibacterial properties of aminotris-(methylenephosphonic) acid. Mater. Chem. Phys. 2010, 119, 330-336. [CrossRef]

26. Kar, P.K.; Singh, G. Evaluation of nitrilotrimethylenephosphonic acid and nitrilotriacetic acid as corrosion inhibitors of mild steel in sea water. ISRN Mater. Sci. 2011, 167487. [CrossRef]

27. Fang, J.L.; Li, Y.; Ye, X.R.; Wang, Z.W.; Liu, Q. Passive films and corrosion protection due to phosphonic acid inhibitors. Corrosion 1993, 49, 266-271. [CrossRef]

28. Chougrani, K.; Boutevin, B.; David, G.; Seabrook, S.; Loubat, C. Acrylate Based Anticorrosion Films Using Novel Bis-Phosphonic Methacrylates. J. Polymer Sci. A Polymer Chem. 2008, 46, 7972-7984. [CrossRef]

29. Fang, J.; Li, J. Quantum chemistry study on the relationship between molecular structure and corrosion inhibition efficiency of amides. J. Mol. Struct. Theochem 2002, 593, 179-185. [CrossRef]

30. Vinutha, M.R.; Venkatesha, T.V. Review on Mechanistic Action of Inhibitors on Steel Corrosion in Acidic Media. Port. Electrochim. Acta 2016, 34, 157-184. [CrossRef]

31. Liu, L.; Cao, T.T.; Zhang, Q.W.; Cui, C.W. Organic Phosphorus Compounds as Inhibitors of Corrosion of Carbon Steel in Circulating Cooling Water: Weight Loss Method and Thermodynamic and Quantum Chemical Studies. Adv. Mater. Sci. Eng. 2018, 1653484. [CrossRef]

32. Hyperchem 7.52 Release for Windows; HyperCube, Inc.: Gainesville, FL, USA, 2002.

33. Jaguar, Version 10.2; Schrödinger, Inc.: New York, NY, USA, 2018.

34. Bochevarov, A.D.; Harder, E.; Hughes, T.F.; Greenwood, J.R.; Braden, D.A.; Philipp, D.M.; Rinaldo, D.; Halls, M.D.; Zhang, J.; Friesner, R.A. Jaguar: A high-performance quantum chemistry software program with strengths in life and materials sciences. Int. J. Quantum Chem. 2013, 113, 2110-2142. [CrossRef]

35. Noor, E.A.; Al-moubaraki, A.; Alghanmi, R. Anti-Corrosive Behavior of Senna Aqueous Extract to Aluminum in Alkaline Solutions. Der Pharma Chem. 2017, 9, 51-59.

36. Almeida, R.M.; Mackenzie, J.D. Infrared absorption and structure of chlorophosphate glasses. J. Non-Cryst. Solids 1980, 40, 535-548. [CrossRef]

37. Gao, X.; Zhao, C.; Lu, H.; Gao, F.; Ma, H. Influence of phytic acid on the corrosion behavior of iron under acidic and neutral conditions. Electrochim. Acta 2014, 150, 188-196. [CrossRef]

38. Yan, R.; Gao, X.; Lv, D.; Ma, H. A study on the differences in morphology and corrosion resistance performance between two different bis(2-ethylhexyl) phosphate self assembled thin films prepared on an iron substrate in water and ethanol solvents. RSC Adv. 2016, 6, 55936-55945. [CrossRef]

39. Chesalov, Y.A.; Chernobay, G.B.; Boldyreva, E.V. Temperature effects on the ir spectra of crystalline amino acids, dipeptides, and polyamino acids. II. L- and DL-serines. J. Struct. Chem. 2008, 49, 627-638. [CrossRef]

40. Sheals, J.; Sjoberg, S.; Persson, P. Adsorption of Glyphosate on Goethite: Molecular Characterization of Surface, Complexes. Environ. Sci. Technol. 2002, 36, 3090-3095. [CrossRef]

41. Lee, J.; Bong, J.; Ha, Y.-G.; Park, S.; Ju, S. Durability of self-assembled monolayers on aluminum oxide surface for determining surface wettability. Appl. Surf. Sci. 2015, 330, 445-448. [CrossRef]

42. Hill, D.; Holliman, P.J.; McGettrick, J.; Appelman, M.; Chatterjee, P.; Watson, T.M.; Worsley, D. Study of the tribological properties and ageing of alkyphosphonic acid films on galvanized steel. Tribol. Internat. 2018, 119, 337-344. [CrossRef]

43. Guerrero, G.; Mutin, P.H.; Vioux, A. Organically modified aluminas by grafting and sol-gel processes involving phosphonate derivatives. J. Mater. Chem. 2001, 11, 3161-3165. [CrossRef]

44. Rahnemaie, R.; Hiemstra, T.; Van Riemsdijk, W.H. Geometry, charge distribution, and surface speciation of phosphate on goethite. Langmuir 2007, 23, 3680-3689. [CrossRef] [PubMed] 
45. Nazari, H.M.; Shihab, M.S.; Havens, E.A.; Shi, X. Mechanism of corrosion protection in chloride solution by an apple-based green inhibitor: Experimental and theoretical studies. J. Infrastruct. Preserv. Resil. 2020, 1-7. [CrossRef]

46. Matos, J.B.; D’Elia, E.; Barcia, O.E.; Mattos, O.R.; Pebere, N.; Tribollet, B. Rotating disc and hemispherical electrodes for copper dissolution study in hydrochloric solution in the presence of benzotriazole. Electrochim. Acta 2001, 46, 1377-1383. [CrossRef]

47. Outirite, M.; Lagrenee, M.; Lebrini, M.; Traisnel, M.; Jama, C.; Vezin, H.; Bentiss, F. ac impedance, X-ray photoelectron spectroscopy and density functional theory studies of 3,5-bis(n-pyridyl)-1,2,4-oxadiazoles as efficient corrosion inhibitors for carbon steel surface in hydrochloric acid solution. Electrochim. Acta 2010, 55, 1670-1681. [CrossRef]

48. Ma, H.; Cheng, X.; Li, G.; Chen, S.; Quan, Z.; Zhao, S.; Niu, L. The influence of hydrogen sulfide on corrosion of iron under different conditions. Corros. Sci. 2000, 42, 1669-1683. [CrossRef]

49. Pajkossy, T. Impedance of rough capacitive electrodes. J. Electroanal. Chem. 1994, 364, 111-125. [CrossRef]

50. Popova, A.; Christov, M.; Vasilev, A. Mono- and dicationic benzothiazolic quaternary ammonium bromides as mild steel corrosion inhibitors. Part II: Electrochemical impedance and polarisation resistance results. Corros. Sci. 2011, 53, 1770-1777. [CrossRef]

51. Elgendy, A.; Nady, H.; El-Rabiei, M.M.; Elhenawy, A.A. Understanding the adsorption performance of two glycine derivatives as novel and environmentally safe anti-corrosion agents for copper in chloride solutions: Experimental, DFT, and MC studies. RSC Adv. 2019, 9, 42120-42131. [CrossRef]

52. Popova, A.; Sokolova, E.; Raicheva, S.; Christov, M. AC and DC study of the temperature effect on mild steel corrosion in acid media in the presence of benzimidazole derivatives. Corros. Sci. 2003, 45, 33-58. [CrossRef]

53. Asan, A.; Kabasakaloğlu, M.; Işıklan, M.; Kılıç, Z. Corrosion inhibition of brass in presence of terdentate ligands in chloride solution. Corros. Sci. 2005, 47, 1534-1544. [CrossRef]

54. Laamari, R.; Benzakour, J.; Berrekhis, F.; Abouelfida, A.; Derja, A.; Villemin, D. Corrosion inhibition of carbon steel in hydrochloric acid $0.5 \mathrm{M}$ by hexamethylenediaminetetramethyl-phosphonic acid. Arab. J. Chem. 2011, 4, 271-277. [CrossRef]

55. Mall, L.D.; Srivastava, V.C.; Agrawal, N.K.; Mishra, I.M. Adsorptive removal of malachite green dye from aqueous solution by bagasse fly ash and activated carbon-kinetic study and equilibrium isotherm analyses. Colloids Surf. A Physicochem. Eng. Asp. 2005, 264, 17-28. [CrossRef]

56. Kavipriya, K.; Rajendran, S.; Sathiyabama, J.; Prabha, A.S. A critical review of corrosion inhibition by phosphonic acids. Eur. Chem. Bull. 2012, 1, 366-374. [CrossRef]

57. Rivera-Grau, L.M.; Casales, M.; Regla, I.; Ortega-Toledo, D.M.; Ascencio-Gutierrez, J.A.; Porcayo-Calderon, J.; Martinez-Gomez, L. Effect of organic corrosion inhibitors on the corrosion performance of 1018 carbon steel in $3 \% \mathrm{NaCl}$ solution. Int. J. Electrochem. Sci. 2013, 8, 2491-2503.

58. Narayanan, R.M.; Gowri, S.; Krishna, M.M. On Line Surface Roughness Measurement Using Image Processing and Machine Vision. In Proceedings of the World Congress on Engineering, London, UK, 2-4 July 2007; WCE: London, UK, 2007.

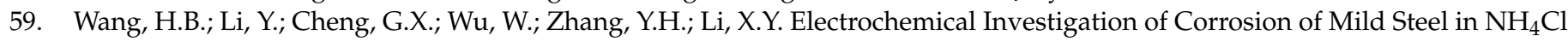
Solution. Int. J. Electrochem. Sci. 2018, 13, 5268-5283. [CrossRef]

60. Popova, A.; Christov, M.; Raicheva, S.; Sokolova, E. Adsorption and inhibitive properties of benzimidazole derivatives in acid mild steel corrosion. Corros. Sci. 2004, 46, 1333-1350. [CrossRef]

61. Chattaraj, P.K.; Maiti, B.; Sarkar, U. Philicity: A unified treatment of chemical reactivity and selectivity. J. Phys. Chem. A. 2003, 107, 4973-4975. [CrossRef]

62. Obot, I.B.; Gasem, Z.M. Theoretical evaluation of corrosion inhibition performance of some pyrazine derivatives. Corros. Sci. 2014, 83, 359-366. [CrossRef]

63. Lgaz, H.; Chung, I.M.; Albayati, M.R.; Chaouiki, A.; Salghi, R.; Mohamed, S.K. Improved corrosion resistance of mild steel in acidic solution by hydrazone derivatives: An experimental and computational study. Arab. J. Chem. 2020, 13, $2934-2954$. [CrossRef]

64. Gomma, M.K.; Wahdan, M.H. Schiff bases as corrosion inhibitors for aluminium in hydrochloric acid solution. Mater. Chem. Phys. 1995, 39, 209-213. [CrossRef]

65. Badawy, W.A.; Ismail, K.M.; Fathi, A.M. Corrosion control of $\mathrm{Cu}-\mathrm{Ni}$ alloys in neutral chloride solutions by amino acids. Electrochim. Acta 2006, 51, 4182-4189. [CrossRef]

66. Helal, N.; Badawy, W. Environmentally safe corrosion inhibition of Mg-Al-Zn alloy in chloride free neutral solutions by amino acids. Electrochim. Acta 2011, 56, 6581-6587. [CrossRef] 